\title{
Optimisation of energy consumption of a solar-electric dryer during hot air drying of tomato slices
}

\author{
Nnaemeka R. Nwakuba \\ Department of Agricultural and Bioresources Engineering, College of Engineering and Engineering Technology, \\ Michael Okpara University of Agriculture, Umudike, Nigeria
}

\begin{abstract}
High-energy demand of convective crop dryers has prompted study on optimisation of dryer energy consumption for optimal and cost effective drying operation. This paper presents response surface optimisation of energy consumption of a solar-electric dryer during hot air drying of tomato slices. Drying experiments were conducted with $1 \mathrm{~kg}$ batch of tomato samples using a $3^{3}$ central composite design of Design Expert 7.0 Statistical Package. Three levels of air velocity $\left(1.0,1.5\right.$ and $\left.2.0 \mathrm{~ms}^{-1}\right)$, slice thickness $(10,15$ and $20 \mathrm{~mm})$ and air temperature $\left(50,60\right.$ and $\left.70^{\circ} \mathrm{C}\right)$ were used to investigate their effects on energy consumption. A quadratic model was obtained with a high coefficient of determination $\left(\mathrm{R}^{2}\right)$ of 0.9825 . The model was validated using the statistical analysis of the experimental parameters and normal probability plot of the energy consumption residuals. Results obtained indicate that the process parameters had significant quadratic effects $(\mathrm{P}<0.05)$ on the energy consumption. The energy consumption varied between $5.42 \mathrm{kWh}$ and $99.78 \mathrm{kWh}$; whereas the specific energy consumption varied between $5.53 \mathrm{kWhkg}^{-1}$ and 150.61 $\mathrm{kWhkg}^{-1}$. The desirability index method was applied in predicting the ideal energy consumption and drying conditions for tomato slices in a solar-electric dryer. At optimum drying conditions of $1.94 \mathrm{~ms}^{-1}$ air velocity, $10.36 \mathrm{~mm}$ slice thickness and $68.4^{\circ} \mathrm{C}$ dry-
\end{abstract}

Correspondence: Nnaemeka Nwakuba, Department of Agricultural and Bioresources Engineering, Michael Okpara University of Agriculture, Umudike, Abia State, Nigeria.

Tel.: +234.803.660.8510.

E-mail: nrnwakuba@gmail.com

Key words: Energy consumption; convective dryer; optimisation; response surface; thermal utilisation; tomato.

Acknowledgements: the efforts of Mr. Oliver Okafor in writing the arduino program, building and installing the electronic components of the solar-electric dryer are deeply appreciated.

Received for publication: 24 May 2018.

Accepted for publication: 21 July 2019.

${ }^{C}$ Copyright: the Author(s), 2019

Licensee PAGEPress, Italy

Journal of Agricultural Engineering 2019; L:876

doi:10.4081/jae.2019.876

This article is distributed under the terms of the Creative Commons Attribution Noncommercial License (by-nc 4.0) which permits any noncommercial use, distribution, and reproduction in any medium, provided the original author(s) and source are credited. ing air temperature, the corresponding energy consumption was $5.68 \mathrm{kWh}$ for maximum desirability index of 0.989 . Thermal utilisation efficiency (TUE) of the sliced tomato samples ranged between $15 \leq \mathrm{TUE} \leq 58 \%$. The maximum TUE value was obtained at $70^{\circ} \mathrm{C}$ air temperature, $1.0 \mathrm{~ms}^{-1}$ air velocity and $10 \mathrm{~mm}$ slice thickness treatment combination, whereas the minimum TUE was obtained at $50^{\circ} \mathrm{C}$ air temperature, $2.0 \mathrm{~ms}^{-1}$ air velocity and $20 \mathrm{~mm}$ slice thickness. Recommendation and prospect for further improvement of the dryer system were stated.

\section{Introduction}

Tomato (Lycopersicon esculentum) is a perishable and seasonal fruit vegetable grown and widely eaten in Nigeria and across the globe for its good health benefits such as reduction of cholesterol, improvement of vision, maintenance of gut, lowering of hypertension, alleviation of diabetes, protection of the skin, prevention of urinary tract infections and gallstones. It is characterised by being in good quality, rich in minerals, vitamins, organic acids, high moisture (usually above $85 \%$ wet basis), crude fibre, high lycopene, ascorbic acid and flavonoids (Abano et al., 2014). In Nigeria, tomato yields about 20-50 tonnes ha $\mathrm{h}^{-1}$ in every harvesting season. Eke (2013) reported that $20-60 \%$ of tomato produced in Nigeria rot away annually. These losses give rise to short supply and high prices during the off-season. This necessitates the need for efficient and adequate preservation techniques to increase its shelf life. Owing to its seasonal and perishable characteristics, drying becomes a good preservation alternative in order to increase its availability. Its drying is facilitated by slicing and spreading out the product to increase their surface area to hot convective air using a reliable heat source and increasing the airflow around the product. In recent times, dried tomatoes have become a highly attractive product for both domestic and industrial purposes which resulted in increased product demand. This is because the lycopene content, characteristic red colour, non-enzymatic browning and vitamin A (ascorbic acid) content are considered as the most vital quality criteria (Abano et al., 2014).

Considerable amount of energy is consumed by convective dryers to dry most freshly harvested agricultural products to safe moisture level as a result of their relatively high moisture content ( 70 to $95 \%$ wet basis) at harvest which requires long drying time, low thermal conductivity during the falling rate drying period which inhibits convective heat transfer to the inner sections of the product structure, relatively low energy efficiency of dryers, and high latent heat of water evaporation (Motevali et al., 2014; Nwakuba et al., 2016). This high-energy consumption, however, has significant impact on the dried product quality such as its nutritional values, shrinkage and other organoleptic properties (Darvishi et al., 2013). Dryer energy consumption is a vital technical information applied for optimal and cost effective design and 
operation of drying systems as well as adequate meeting of safe storage conditions of crops (Nwakuba et al., 2016). Energy consumption has been identified to vary with crop type, moisture content at harvest, final desired moisture content, specific heat capacity of crop, latent heat of vaporisation of water, intended use, gross mass, size, shape, and biological characteristics (such as surface texture, crop porosity, nutritional content), drying times, production capacity, drying air temperatures as well as operating pressure and dryer efficiency (Billiris et al., 2011). Considerable energy savings in drying application can be achieved through partial or full replacement of conventional fuels by renewable energy sources. Extensive research regarding energy consumption of crop dryers has been prompted by the considerable energy consumption in the drying industry, as well as concerns for cost of drying agricultural products, its impact on the food supply chain, and environmental effects like increased prevalent ambient air temperature, increase in greenhouse gas, air pollution, etc. (Koyuncu et al., 2007; Nwakuba et al., 2016). Other reasons prompting the study of energy consumption include: estimating the quantity of fossil fuel saved when using solar energy and the quantity of $\mathrm{CO}_{2}$ emitted into the atmosphere (Tripathy and Kumar, 2009); estimation of the optimum quantity of drying air temperature, air flow, and drying time most appropriate for a particular crop so as to avoid undermining the functional and sensory properties of the product; applicability in the design of appropriate cost and energy effective drying system which would require minimal quantity for any crop type; and for simulation of drying systems.

The use of solar energy as a practical power source for crop drying has been stimulated in recent times due to shortages of oil and natural gas fuels and increase in the cost and depletion of fossil fuels (Nwajinka and Onuegbu, 2014). This power source has been harnessed for heating, cooling, drying, irrigation, pumping, and other numerous thermal processes in food industries (Itodo et al., 2002). Over $90 \%$ of agricultural products are sun-dried in Nigeria and in most African countries (Arinze et al., 1990). Unfortunately, much of this commonly available, renewable and affordable energy from the sun is wasted due to lack of adequate technology to harness it. The daily and seasonal fluctuations in solar radiation as well as its frequent absorption by rain and persistent cloud cover in most parts of the country and the world at large have hampered the optimal use of the Sun's energy for crop drying operation and therefore necessitate the additional use of energy source that permits drying operation during low irradiation and night periods. Researchers Ferreira et al. (2007), Sarsavadia (2007) and Nwakuba et al. (2017) have incorporated electricity as a viable auxiliary source of energy in solar drying systems due to its nonpolluting characteristics, ease of usage and high heat density. The increased emphasis on rural development in Nigeria which undoubtedly will necessitate increase in energy demand in the rural sector for drying and other agricultural processes, makes the use of solar-electric dryers cost effective and environmentally friendly. Reducing the energy consumption in these systems irrespective of the crop to be dried would grossly improve the dryer economy. Since the sliced tomato price and quality are functions of energy consumption during drying, it is essential to select optimal drying variables that would yield minimal energy and carbon footprint on the natural environment while keeping the nutritional quality of the sliced tomato unabated and intact with minimal deterioration. The objective of this study is to investigate the effects of the drying variables (air velocity, sample thickness, and drying air temperature) on the total and specific energy consumption of a solar-electric dryer and to optimise the energy consumption of tomato slices during hot air drying.

\section{Materials and methods}

\section{Sample preparation}

A local variety of fresh tomato samples (Gboko Spp.) were procured from a fruit market in Owerri, Imo State, Nigeria. The samples were selected based on uniform colour, and carefully sorted to remove damaged or septic ones, and classified according to relative size, washed and sliced in three layer thicknesses $(10,15$ and $20 \mathrm{~mm}$ ) using a sharp stainless steel knife and a vernier caliper (accuracy $0.05 \mathrm{~mm}$ ) with the direction of cutting perpendicular to the vertical axis of the tomato samples. The initial mass of the sliced samples was measured by a digital weighing balance (of accuracy 0.01 g; Camry instruments, China) and the samples placed on drying racks in such a way that the drying air flows axially into the sample matrix (for faster drying) in thin layers. The mean initial moisture content of $19.57 \mathrm{~kg}$ water/dry weight of the samples was determined gravimetrically measured by drying $20 \mathrm{~g}$ of representative sliced samples at $105^{\circ} \mathrm{C}$ for $24 \mathrm{~h}$ (Koyuncu et al., 2007; Darvishi et al., 2013).

\section{Drying system and experimental procedure}

The solar-electric dryer (Figure 1) was switched on and the required airflow and temperature were selected using a $4 \times 4$ matrix keypad panel on the control unit. The nucleus of the crop dryer is the arduino microprocessor which controls the overall operation of the system and automates temperature and humidity control, air flow, sample weight loss, and energy consumption through the use of weight sensors and transducers (thermistor and humidity sensors) placed on five locations of the drying system viz: drying racks, solar collector box, inlet and outlet points. The drying chamber was allowed to maintain a steady-state condition (i.e. a state of uniform air temperature and relative humidity maintained in the drying chamber) before the sliced samples were introduced. The dryer was operated at three varying air temperature thresholds $(50,60$ and $70^{\circ} \mathrm{C}$ ), air velocities $\left(1.0,1.5\right.$ and $\left.2.0 \mathrm{~ms}^{-1}\right)$ and slice thicknesses $(10,15$ and $20 \mathrm{~mm})$. Sliced tomato samples $(1000 \mathrm{~g})$ were placed on the drying racks, side-by-side in thin layers, in such a way that each sliced sample/layer was placed axially to the direction of heat flow for uniform drying. The system was programmed via the arduino micro-processor, to measure and record the energy consumption and weight loss in 30 min interval as well as the air temperature and relative humidity of the five points on the dryer. The amount of moisture loss was recorded using a weight sensor attached to the weighing balance in the drying chamber (Figure 1, $\mathrm{S} / \mathrm{N}$ 18). Drying of each batch was stopped when constant mass was observed. The amount of electrical energy consumed, drying rate and time for each sample batch (at varying air velocities, slice thicknesses, and temperatures) were measured and recorded by the micro-processor, whereas the amount of solar flux incident on the solar collector was measured by a pyranometer (Apogee MP-200), the specific energy consumption calculated and thermal utilisation of efficiency of the system were calculated. The experiment was repeated three times for different air velocities, sample layer thicknesses and drying air temperatures for a constant batch size of $1 \mathrm{~kg}$.

\section{Experimental design and data analysis}

The response surface methodology (RSM) of Design Expert version 7.0 (Stat ease Inc., Minneapolis, MN, USA) statistical package was used to design and analyse the drying experiments as well as determining the relative contributions of the three independent variables (air velocity, A: 1.0, 1.5 and $2.0 \mathrm{~ms}^{-1}$; sample slice 
thickness, S: 10, 15 and $20 \mathrm{~mm}$; and drying air temperature, T: 50, 60 and $70^{\circ} \mathrm{C}$ ) to energy consumption $\left(\mathrm{E}_{\mathrm{C}}\right)$ responses. A three-factor and three-level $\left(3^{3}\right)$ central composite design (CCD) of RSM arrangements was applied to evaluate the linear (main), interactive and quadratic (curvature) effects of the process parameters, to optimise the energy consumption of a convective solar-electric during the drying process of tomato slices. The central composite design used has 20 experimental runs and the experimental order had been completely randomised to reduce unexplainable variability effects from the experimental responses. Multiple regression approach was employed using the method of least squares in the data analyses. The response of the experimental values was expressed as Equation (1) by a second order polynomial function:

$V_{R}=\beta_{0}+\beta_{1} A+\beta_{2} S+\beta_{3} T+\beta_{11} A^{2}+\beta_{22} S^{2}+\beta_{33} T^{2}+\beta_{12} A S+\beta_{13} A T+\beta_{23} S T$

where: $V_{R}=$ response variable $\left(E_{s p}, k W h\right) ; A, S$ and $T$ represent air velocity $\left(\mathrm{ms}^{-1}\right)$, slice thickness $(\mathrm{mm})$ and temperature $\left({ }^{\circ} \mathrm{C}\right)$ respectively; $\beta_{0}=$ constant regression coefficient; $\beta_{1}, \beta_{2}$ and $\beta_{3}$ linear regression coefficients; $\beta_{11}, \beta_{22}$ and $\beta_{33}=$ quadratic regression coefficients; $\beta_{12}, \beta_{13}$ and $\beta_{23}=$ interaction or cross-product regression coefficients.

The actual and coded values of the variables are presented in Table 1. The test for level of statistical significance was conducted on the total error criteria, having 95\% level of confidence. Analysis of variance (ANOVA) was used to determine the significant variables in the model for the response of energy consumption. The model adequacies were checked by calculating $R^{2}$, adjusted $R^{2}$, adequate precision, PRESS and $\mathrm{CV}$, whereas response surface optimisation was conducted using numerical optimisation technique. Desired goals (minimisation of energy consumption) was adopted to perform optimisation of process variables and the response. A multivariate response method, also referred to as overall desirability function or index, DI (Kumar et al., 2011; Abano et al., 2014) expressed as Equation (2) was also used:

$$
D_{i}=\left(Y_{1} \times Y_{2} \times \ldots, Y_{n}\right)^{\frac{1}{n}}
$$

where: $Y_{i}(i=1,2,3, \ldots, n)=$ responses; $n=$ total number of responses; $0 \leq D_{i} \leq 1$, with 0 and 1 being the least and most desirable coded levels respectively. $\mathrm{D}_{\mathrm{i}}=$ desirability index or composite function illustrating how well matched or desirable the experimental responses are at a given level of independent/input variables. The RSM optimisation process involves goals and priorities for input and response variables (Abano et al., 2014). This study considers goal for the input variables at any level within the design value range, whereas the response variable was minimum energy consumption.

Table 1. Factor levels of the actual and coded variables of the response surface methodology factorial design.

\begin{tabular}{lccc} 
Process variable & Symbol & \multicolumn{2}{c}{ Levels } \\
Air velocity $\left(\mathrm{ms}^{-1}\right)$ & $\mathrm{A}$ & 1.0 & -1 \\
& & 1.5 & 0 \\
& & 2.0 & 1 \\
Slice thickness $(\mathrm{mm})$ & $\mathrm{S}$ & 10 & -1 \\
& & 15 & 0 \\
& & 20 & 1 \\
\hline Temperature $\left({ }^{\circ} \mathrm{C}\right)$ & $\mathrm{T}$ & 50 & -1 \\
& & 60 & 0 \\
& & 70 & 1 \\
\hline
\end{tabular}

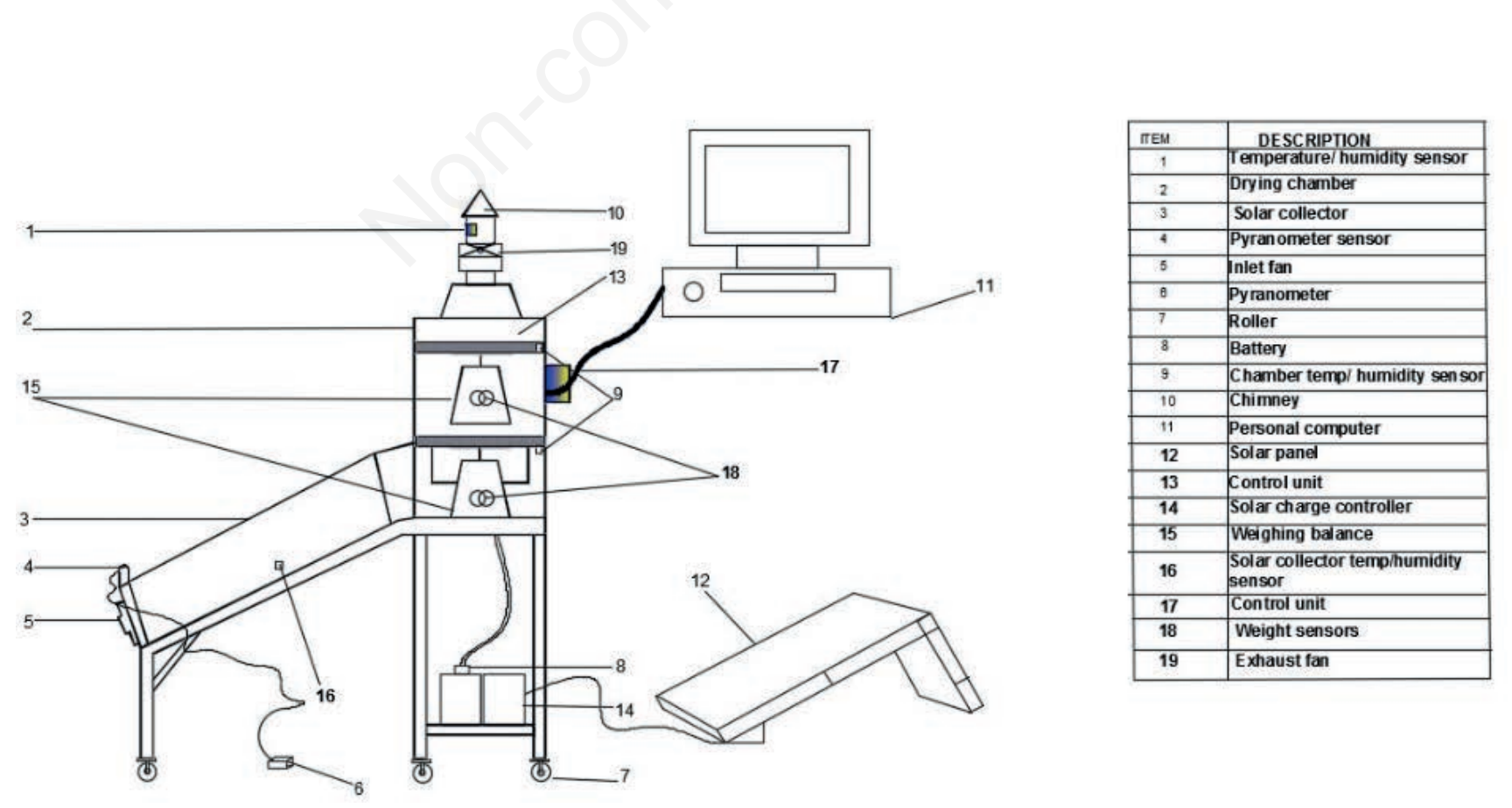

Figure 1. Schematics of the solar-electric drying system. 


\section{Energy consumption of sliced tomato drying}

The total energy consumed by $1 \mathrm{~kg}$ batch of the sliced tomato samples in the solar-electric crop dryer at varying air velocities, slice thicknesses, and air temperatures is expressed in Equation (3) (Afolabi et al., 2014; Koyuncu et al., 2007) as:

$\mathrm{E}_{\mathrm{T}}=\mathrm{AV} \rho_{\mathrm{a}} \mathrm{C}_{\mathrm{pa}} \Delta \mathrm{TD}_{t}$

where: $\mathrm{A}=$ area of rack $\left(\mathrm{m}^{2}\right), \mathrm{V}=$ air velocity $\left(\mathrm{ms}^{-1}\right), \rho_{\mathrm{a}}=$ air density $\left(\mathrm{kgm}^{-3}\right), \mathrm{D}_{\mathrm{t}}=$ total drying time per batch $(\mathrm{h}), \Delta \mathrm{T}=$ temperature difference between ambient and hot air $\left({ }^{\circ} \mathrm{C}\right)$, and $\mathrm{C}_{\mathrm{pa}}=$ specific heat of air $\left(\mathrm{kJkg}^{-1}{ }^{\circ} \mathrm{C}\right)$;

The specific energy consumption is expressed by Equation (4) (Koyuncu et al., 2007; Afolabi et al., 2014; Minaei et al., 2014) as:

$$
E_{S P}=\frac{E_{T}}{M_{0}}
$$

where: $\mathrm{E}_{\mathrm{T}}=$ total energy consumption per batch $(\mathrm{kWh})$; $\mathrm{E}_{\mathrm{sp}}=$ specific energy consumption $\left(\mathrm{kWhkg}^{-1}\right) ; \mathrm{M}_{\mathrm{o}}=$ initial sample mass (kg).

The total energy consumption $\left(\mathrm{E}_{\mathrm{T}}\right)$ of the dryer in drying a batch $(1 \mathrm{~kg})$ of sliced tomato samples at varying drying conditions was obtained by adding the energy directly measured by the arduino micro-processor in 30 minutes intervals to the solar energy absorbed by the solar collector (measured by the pyranometer). The measured $\mathrm{E}_{\mathrm{T}}$ was compared with the calculated (from Equation 1), which was less by an average of $8.14 \%$ of the calculated $\mathrm{E}_{\mathrm{T}}$ values. This marginal difference was as a result of the constant air density and air velocity used in the calculated $\mathrm{E}_{\mathrm{T}}$ values; whereas in the measured $\mathrm{E}_{\mathrm{C}}$ values, varying air velocities were considered by the arduino-primed dryer system where air densities vary with air temperature, thus a negligible value difference. The calculated $\mathrm{E}_{\mathrm{T}}$ values were used to calibrate the arduino micro-controller as well as validating the system-measured $\mathrm{E}_{\mathrm{T}}$ values.

\section{Thermal utilisation efficiency}

The themal utilisation efficiency (TUE) shows how well a drying system converts thermal energy or accomplishes heat transfer process during drying operation. It is referred to as the ratio of latent heat of evaporation of sample internal water to the energy consumption for moisture evaporation from free water. TUE was determined using Equation (5) (Minaei et al., 2014; Beigi, 2016):

$$
\eta_{\text {th }}=\frac{W_{A_{s}} L_{v}\left(M_{i}-M_{f}\right)}{Q t\left(100-M_{f}\right)}
$$

where: $\eta_{\text {th }}=$ thermal utilisation efficiecy (\%); $\mathrm{W}=$ weight density of sample $\left(\mathrm{kgm}^{-2}\right) ; \mathrm{A}_{\mathrm{S}}=$ total sample area $\left(\mathrm{m}^{2}\right) ; \mathrm{L}_{\mathrm{V}}=$ latent heat of vaporisation $\left(\mathrm{kJkg}^{-1}\right) ; \mathrm{M}_{\mathrm{i}}$ and $\mathrm{M}_{\mathrm{f}}=$ initial and final moisture contents respectively (\%w.b); $\mathrm{Q}=$ power of the heat source $(\mathrm{kW}) ; \mathrm{t}=$ operation time of the heat source (minutes).

The latent heat of evaporation of the sliced samples was considered equal to the latent heat at ambient air pressure (Minaei et al., 2014).

\section{Results and discussion}

\section{Effect of drying parameters on energy consumption}

The energy consumption responses of the twenty experimental runs performed at varying process variables with CCD are presented in Table 2. The experimental data were used to determine the coefficients of the independent/input variables, as well as the interactions between them (Table 3). Experimental results of the second order quadratic model fitted to the response variable (energy consumption) in terms of the coded variables is given in Equation (6) as:

$E_{c}=22.07-8.58 \mathrm{~A}+23.43 \mathrm{~S}-23.98 \mathrm{~T}+20.01 \mathrm{~A}^{2}+5.77 \mathrm{~S}^{2}+21.81 \mathrm{~T}^{2}-4.27 \mathrm{AS}-$

9.39AT $-7.13 \mathrm{ST} \quad\left[\mathrm{R}^{2}=0.9825\right]$

where: A, S and T are the coded values of air velocity $\left(\mathrm{ms}^{-1}\right)$, sample slice thickness $(\mathrm{mm})$, and temperature $\left({ }^{\circ} \mathrm{C}\right)$ respectively; $\mathrm{E}_{\mathrm{c}}=$ energy consumption $(\mathrm{kWh})$.

Analysis of variance (ANOVA) of Equation (1) (Table 3) indicates that $\mathrm{P}$-values for linear terms had significant effect on energy consumption $(\mathrm{P}<0.05)$. Equation $(6)$ shows that variables $\mathrm{A}$ and $\mathrm{T}$ had negative coefficients, whereas $\mathrm{S}$ was positive. This implies that increase in air velocity and temperature may reduce the energy consumption significantly and further increase in the sample slice thickness may increase the energy consumption quantitatively.

Table 2. Central composite design for three experimental factors of the process variables and responses (energy consumption and

\begin{tabular}{|c|c|c|c|c|}
\hline Run No. & $\begin{array}{l}\text { Actua } \\
\text { A }\left(\mathrm{ms}^{-1}\right)\end{array}$ & $\begin{array}{l}\text { process } \\
\mathrm{S}(\mathrm{mm})\end{array}$ & $\begin{array}{l}\text { iriables } \\
\mathrm{T}\left({ }^{\circ} \mathrm{C}\right)\end{array}$ & $\begin{array}{c}\text { Response variables } \\
\text { EC (kWh) }\end{array}$ \\
\hline 1 & 1.05 & 6.93 & 60.00 & 30.9 \\
\hline 2 & 2.00 & 19.00 & 70.00 & 43.5 \\
\hline 3 & 1.05 & 14.50 & 76.82 & 93.0 \\
\hline 4 & 1.05 & 14.50 & 60.00 & 80.0 \\
\hline 5 & 1.05 & 22.07 & 60.00 & 83.9 \\
\hline 6 & 1.05 & 14.50 & 60.00 & 80.0 \\
\hline 7 & -0.55 & 14.50 & 60.00 & 85.1 \\
\hline 8 & 1.05 & 14.50 & 60.00 & 80.0 \\
\hline 9 & 1.05 & 14.50 & 60.00 & 80.0 \\
\hline 10 & 2.00 & 19.00 & 50.00 & 70.6 \\
\hline 11 & 0.10 & 10.00 & 50.00 & 32.0 \\
\hline 12 & 1.05 & 14.50 & 43.18 & 86.5 \\
\hline 13 & 1.05 & 14.50 & 60.00 & 80.0 \\
\hline 14 & 1.05 & 14.50 & 60.00 & 80.0 \\
\hline 15 & 2.00 & 10.00 & 70.00 & 22.5 \\
\hline 16 & 0.10 & 10.00 & 70.00 & 42.0 \\
\hline 17 & 0.10 & 19.00 & 70.00 & 70.0 \\
\hline 18 & 2.65 & 14.50 & 60.00 & 31.9 \\
\hline 19 & 2.00 & 10.00 & 50.00 & 42.4 \\
\hline 20 & 0.10 & 19.00 & 50.00 & 102.0 \\
\hline
\end{tabular}
lycopene content). 
From the ANOVA, the quadratic energy model is highly significant at $\mathrm{P}<0.05$, with a high coefficient of determination $\left(\mathrm{R}^{2}\right)$ of 0.9825 . This illustrated that a greater percentage of the experimental variability was described by the RSM model (Abano et al., 2014). A coefficient of variability (CV) less than $10 \%$ was observed (Giri and Prasad, 2007; Kumar et al., 2011), and it indicates that the quadratic model adequately represented the experimental data and closely predicted the energy consumption of the solar-electric dryer for drying of tomato slices as observed by Kumar et al. (2011). The suitability of the second-order quadratic model was further validated with the normal probability plot of the energy consumption residuals as shown in Figure 2A, and the predicted and experimental energy consumption plot (Figure 2B). The close- ness of the plotted data (of both plots) to the straight line showed equality between the predicted and experimental energy consumption values as well as indicating that no problem existed between the normality and severity of outliers in the experimental data of energy consumption. The positive coefficients of the quadratic terms of AST factors show positive quadratic effect on energy consumption of the dryer. The interaction or cross-product effect of the process variables on energy consumption of solar-electric dried tomato sliced samples is presented in response surface plots (Figure $3 \mathrm{~A}$ and $\mathrm{C}$ ). The cross-product interaction effect between air velocity and slice thickness, air velocity and air temperature, as well as the quadratic effect of air velocity were insignificant $(\mathrm{P} \geq 0.05)$ to energy consumption, whereas other terms were signif-

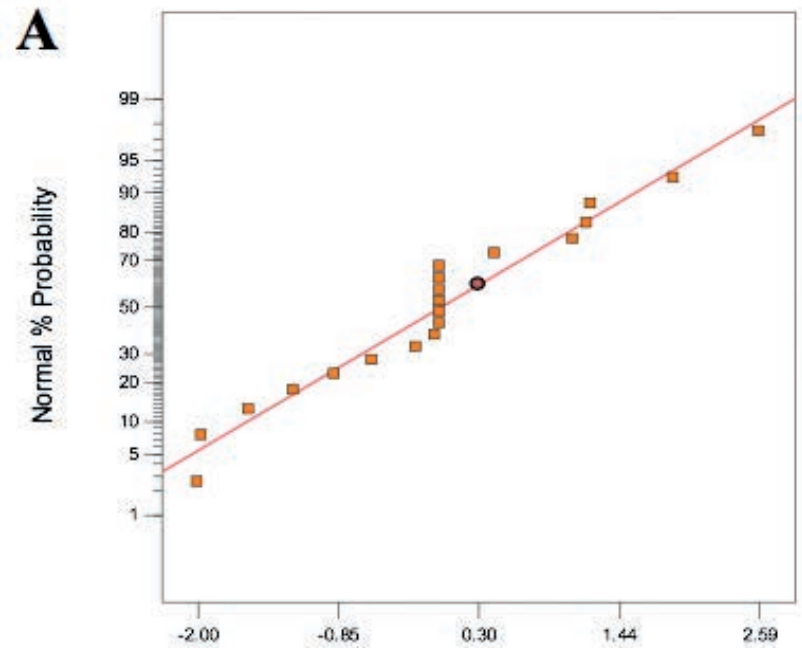

Energy consumption residuals
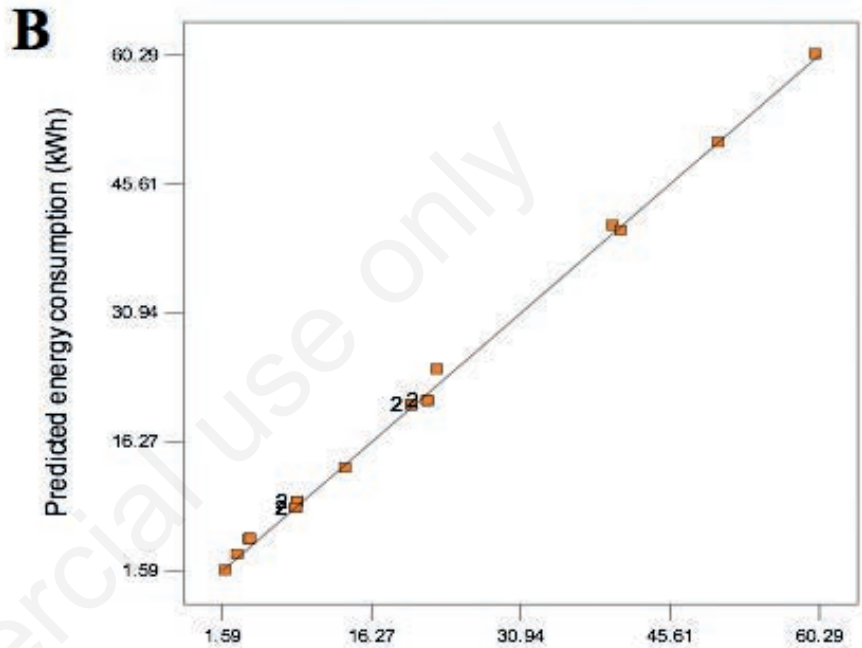

Experimental energy consumption ( $\mathrm{kWh}$ )

Figure 2. A) Normal probability plot of the energy consumption residuals; B) predicted versus experimental energy consumption.

Table 3. Analysis of variance for energy consumption at varying drying conditions by response surface quadratic model.

\begin{tabular}{|c|c|c|c|c|c|c|}
\hline Source & Degrees of freedom & Coefficient estimate & Sum of squares & Mean square & F-value & $\begin{array}{l}\text { P-value } \\
\text { Prob > F }\end{array}$ \\
\hline Intercept $\left(\beta_{0}\right)$ & 9 & 22.07 & & & & \\
\hline Model & 1 & & $14,383.43$ & 1598.16 & 7.81 & $<0.0001^{*}$ \\
\hline A - Air velocity & 1 & -8.58 & 589.45 & 589.45 & 12.60 & $0.0392 *$ \\
\hline S - Slice thickness & 1 & 23.43 & 4393.59 & 4393.59 & 28.73 & $<0.0011^{*}$ \\
\hline T- Temperature & 1 & -23.98 & 4600.80 & 4600.80 & 1.74 & $<0.0001^{*}$ \\
\hline $\mathrm{A}^{2}$ & 1 & 20.01 & 1686.32 & 1686.32 & 11.62 & $0.5247^{\mathrm{ns}}$ \\
\hline $\mathrm{S}^{2}$ & 1 & 5.77 & 140.42 & 140.42 & 12.48 & $0.0002 *$ \\
\hline $\mathrm{T}^{2}$ & 1 & 21.81 & 2002.39 & 2002.39 & 14.12 & $<0.0001^{*}$ \\
\hline $\mathrm{A} \times \mathrm{S}$ & 1 & -4.27 & 73.02 & 73.02 & 2.09 & $0.0714^{\mathrm{ns}}$ \\
\hline $\mathrm{A} \times \mathrm{T}$ & 1 & -9.39 & 352.69 & 352.69 & 1.55 & $0.3301^{\mathrm{ns}}$ \\
\hline $\mathrm{S} \times \mathrm{T}$ & 1 & -7.13 & 203.21 & 203.21 & 2.12 & $0.0032^{*}$ \\
\hline Residual & 7 & - & 21.12 & - & - & - \\
\hline Lack of fit & 3 & - & 5.47 & - & - & - \\
\hline Pure error & 4 & - & 0.00 & - & - & - \\
\hline Cor. Total & 16 & - & $14,390.54$ & - & - & - \\
\hline CV & & & 3.9 & & & \\
\hline
\end{tabular}

*Significant; ns not significant; lack of fit is not significant at $\mathrm{P}>0.05$. 
icant $(\mathrm{P}<0.05)$. As illustrated in Table 3 and Figure 3A-C, energy consumption of the solar-electric dryer had a significant decrease as air velocity and air temperature were increased. Air temperature had the highest effect on energy consumption $(<0.0001)$, followed by the slice thickness $(<0.0011)$ then the air velocity $(<0.0392)$. The minimum total energy consumption $(5.42 \mathrm{kWh})$ was obtained at the highest drying air temperature, air velocity and least slice thickness, whereas the maximum energy consumption (99.78 $\mathrm{kWh}$ ) was obtained at the least air velocity, air temperature and thickness slice sample (Figure 3A and C). At increased air temperature and air velocity, mean energy consumption reduced; greater heat transfer rate and water pressure deficit occurred, more convective air entered the drying chamber to increase surface moisture evaporation rate as well as increasing the sample kinetic energy of internal moisture for rapid diffusion and reduced resistance to capillary transport. This gave rise to increased heat and moisture diffusion and evaporation is accomplished in a shorter time, thereby reducing the amount of energy consumption which is a function of drying time. Similar trend was observed in the works of Abano et al. (2014), Minaei et al. (2014), and Sepehrimehr and Kohan (2015).

At reduced air velocity, more energy was consumed when drying thicker sliced tomato samples (Figure 3B). This was as a result of gross reduction in mass transfer rate and increased capillary distance for moisture diffusion. With increased drying air temperature and decreased sample slice thickness, less energy was consumed
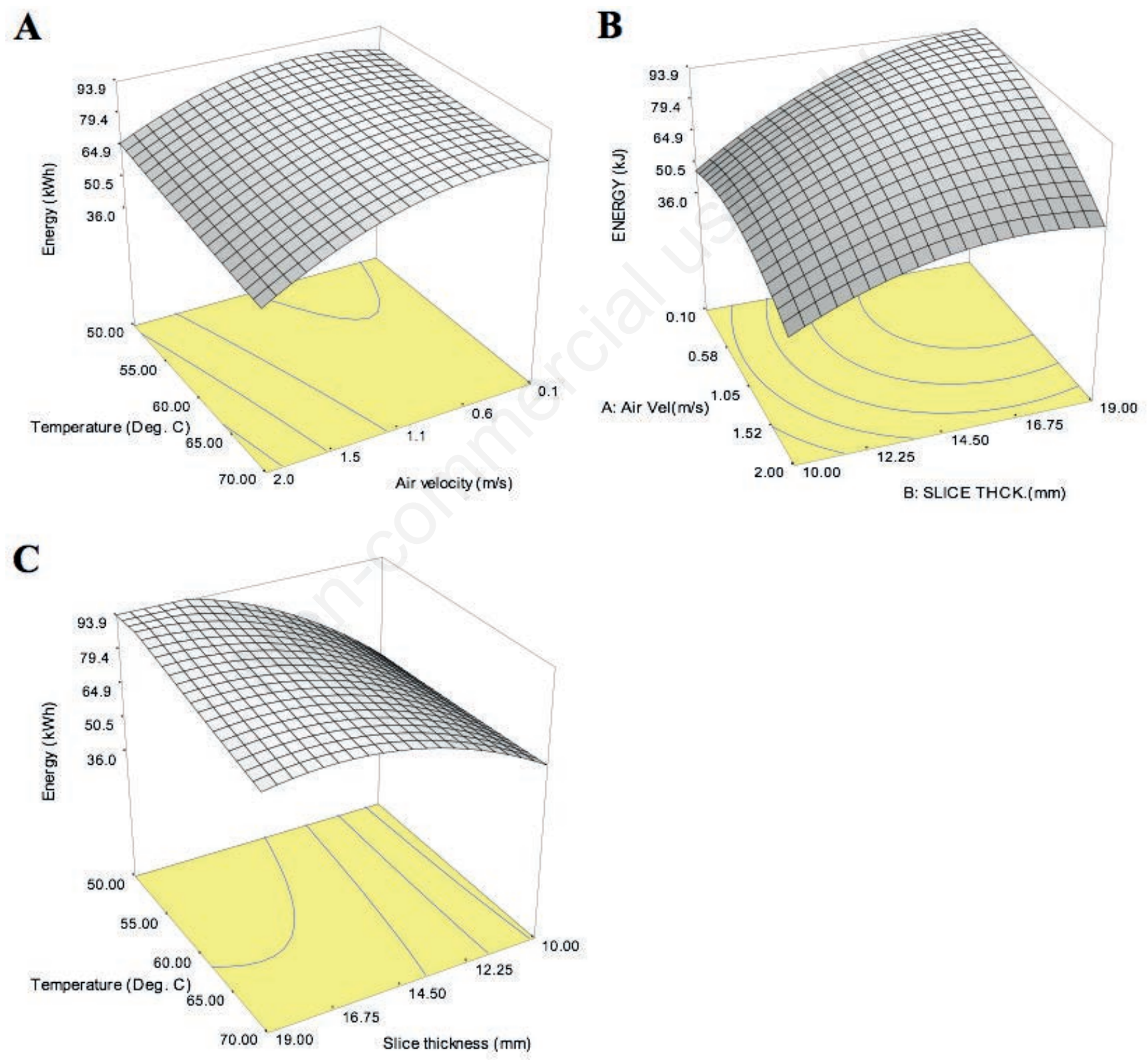

Figure 3. Response surface plot showing: A) the effect of air velocity and temperature; B) air velocity and slice thickness; C) slice thickness and temperature on energy consumption. 
(Figure 3C), since more moisture diffused at increased air temperature and drying time decreased, thus the reduction in energy consumption.

\section{Specific energy consumption}

The specific energy consumption for drying a batch of the sliced tomato samples at varying process parameters is presented in Figure 4. Specific energy consumption decreased with decrease in slice thickness at any given air temperature and air velocity. The maximum specific energy consumption (150.6 $\left.\mathrm{kWhkg}^{-1}\right)$ was obtained at the $20 \mathrm{~mm}$ slice thickness. It also decreased with increase in air temperature at constant air velocity and slice thickness. This is because with increasing material thickness, the total energy consumption increases as it is divided by a constant initial sample weight. Specific energy consumption was thus calculated by substituting the measured value of the total consumed energy obtained from the arduino micro-processor as well as the initial sample weight into Equation (4).

It is evident that air velocity, air temperature and slice thickness had remarkable effects on the specific energy consumption of the solar-electric dryer. Increase in drying air temperature reduced the specific energy consumption since more moisture was removed in a shorter time per sample batch size. Drying a larger sample thickness at a low air temperature and air velocity increased the specific energy consumption. This is because, more time was taken for the larger sample layer to diffuse internal moisture to the product surface before the slow-moving convective air evaporates the surface moisture, thus increased drying time and energy. The maximum and minimum specific energy consumption $\left(150.61 \mathrm{kWhkg}^{-1}\right.$ and 5.53 $\mathrm{kWhkg}^{-1}$ respectively) were obtained at the first and last drying parameter regimes: $50^{\circ} \mathrm{C}, 20 \mathrm{~mm}, 1.0 \mathrm{~ms}^{-1}$ and $70^{\circ} \mathrm{C}, 10 \mathrm{~mm}, 2$ $\mathrm{ms}^{-1}$ respectively. This generally implied that less energy was con- sumed at increased air temperature and air velocity for drying any sample thickness. This corroborated with the findings of Sharma and Prasad (2006) for glarlic cloves, Jindarat et al. (2011) for nonhygroscopic materials, Afolabi et al. (2014) for ginger slices, ElMesery and Mwithiga (2012) for onions slices with a decreasing trend in specific energy consumption with increase in the drying air temperature and air velocity.

\section{Optimisation of energy consumption}

The concept of overall desirability function (Equation 2) of Design Expert 7.0 version was used to affirm the position of the optimal energy consumption of the solar-electric dryer. The desired objective (goal) for each input parameter and responses were allotted to each parameter to make adjustment for its desirability index (Table 4). The optimum values of the process parameters yielded an overall desirability function of 0.989 at $98 \%$ confidence level in the range of the process parameters, which yielded an optimal energy consumption of $5.68 \mathrm{kWh}$ for $1.94 \mathrm{~ms}^{-1}, 68.4^{\circ} \mathrm{C}$, and $10.36 \mathrm{~mm}$ air velocity, air temperature and slice thickness respectively. The optimisation process of the solar-electric dryer gets better as the desirability function is close to unity. Interestingly, these predicted values though had little deviation from their corresponding experimental input variables but were still within the range (Table 4). Therefore, the quadratic model obtained from this study (Equation 6) could be applied in the optimisation of energy consumption of solar-electric dryers during drying of sliced tomato samples.

\section{Thermal utilisation efficiency}

The thermal utilisation efficiency (TUE) of the solar dryer at varying air velocities, slice thicknesses and air temperatures was calculated using Equation (5), and the results were presented in Figure 5. TUE increased with increasing drying air temperature at

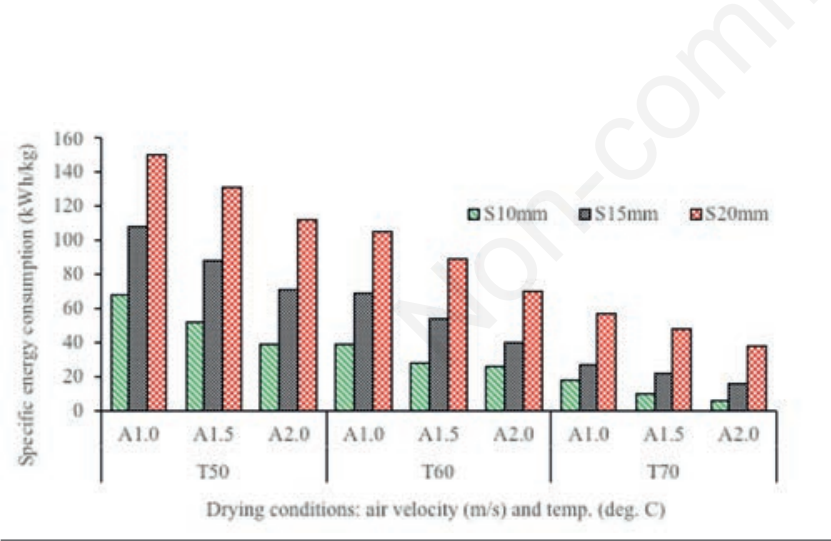

Figure 4. Specific energy consumption of the solar-electric dryer for drying a batch of tomato slices.

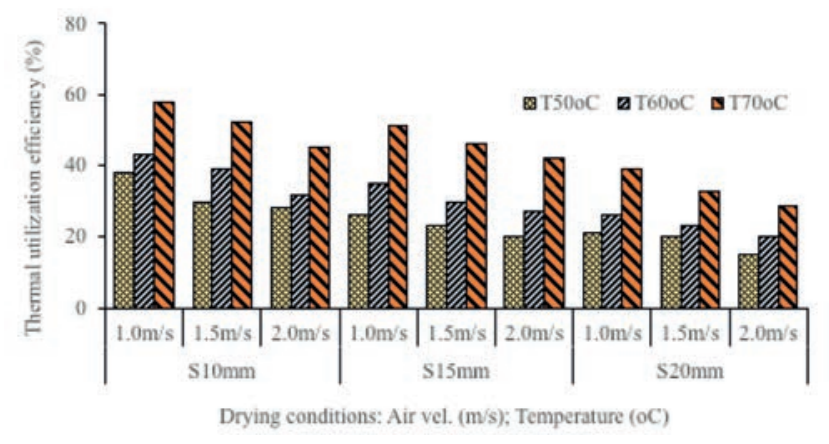

Figure 5. Thermal utilisation efficiency of the solar-electric dryer at varying drying conditions.

Table 4. Objective function and criteria for optimisation of process factors and response.

\begin{tabular}{|c|c|c|c|c|c|c|}
\hline \multirow{2}{*}{ Responses } & \multirow[t]{2}{*}{ Goal } & \multicolumn{2}{|c|}{ Lower limit } & \multicolumn{2}{|c|}{ Upper limit } & \multirow[t]{2}{*}{ Importance } \\
\hline & & Actual & Coded & Actual & Coded & \\
\hline Air velocity $\left(\mathrm{ms}^{-1}\right)$ & In range & $1 \mathrm{~ms}^{-1}$ & -1 & $2 \mathrm{~ms}^{-1}$ & 1 & 3 \\
\hline Temperature $\left({ }^{\circ} \mathrm{C}\right)$ & In range & $50^{\circ} \mathrm{C}$ & -1 & $70^{\circ} \mathrm{C}$ & 1 & 3 \\
\hline Slice thickness (mm) & In range & $10 \mathrm{~mm}$ & -1 & $20 \mathrm{~mm}$ & 1 & 3 \\
\hline Energy consumption (kWh) & Minimise & - & & - & - & 3 \\
\hline
\end{tabular}


constant air velocity and slice thickness, and decreased with increase in air velocity and slice thickness. This was because higher drying air temperatures result in further reduction of moisture, which increased energy utilisation efficiency. These observations are in line with Aviara et al. (2014) on tray drying of cassava starch; Azadbakht et al. (2017) on eggplant drying in a fluidised bed dryer. The maximum TUE value was obtained at $70^{\circ} \mathrm{C}$ air temperature, $1.0 \mathrm{~ms}^{-1}$ air velocity and $10 \mathrm{~mm}$ slice thickness, whereas the minimum TUE was obtained at $50^{\circ} \mathrm{C}$ air temperature, $2.0 \mathrm{~ms}^{-1}$ air velocity and $20 \mathrm{~mm}$ slice thickness. These results agreed with those reported in the literature (Sarsavadia, 2007; El-Mesery and Mwithiga, 2012; Minaei et al., 2014; Motevali et al., 2014).

Since TUE is the ratio of energy used for water evaporation to energy consumed (supplied), with increased slice thickness, part of the utilised heat was used to increase the product temperature so as to overcome the energy barrier (activation energy level) as a result of longer capillary distance and initiate mass diffusion, thereby leaving a little amount of heat for surface moisture evaporation, thus low thermal efficiency. However, with decreasing slice thickness, TUE increased due to increase in the interface between the product and the drying air (Azadbakht et al., 2017). Drying air at low velocity tends to have more resident time of contact with the drying sample and evaporates the surface moisture more efficiently than when it is at a higher velocity, which may create turbulence at the inlet and plenum of the drying chamber and exits without having much contact effect on the samples. From Figure 5, it is evident that TUE of the convective solar dryer is a function of the heat source performance and initial weight of the product sample, since the initial and final moisture contents as well as the latent heat of vaporisation of water were considered constant (Minaei et $a l ., 2014)$. High TUE of the system is related to good performance of the heating units, which are controlled by the microprocessor to regulate the drying air temperature within a preset threshold at regulated air velocities.

\section{Conclusions}

Optimisation of energy consumption of a solar-electric dryer was studied using sliced fresh tomato samples at varying process parameters (air velocity, A: $1.0,1.5$ and $2.0 \mathrm{~ms}^{-1}$; slice thickness, S: 10,15 and $20 \mathrm{~mm}$; air temperature, A: 50,60 and $70^{\circ} \mathrm{C}$ ) using a $3^{3}$ central composite design of Design Expert 7.0 statistical package to investigate the effects of the process parameters on the response variable (energy consumption). The AST factors had significant quadratic effects $(\mathrm{P}<0.05)$ on the energy consumption of the solar-electric dryer. The quadratic energy model was highly significant at $\mathrm{P}<0.05$, with a coefficient of determination $\left(\mathrm{R}^{2}\right)$ of 0.9825 , which had CV less than $10 \%$ indicating adequate representation of the experimental data and accurate prediction of energy consumption.

Drying air temperature had the highest effect on energy consumption, followed by slice thickness and air velocity, respectively. Energy consumption had a significant decrease as air velocity and air temperature were increased. The minimum energy consumption $(5.42 \mathrm{kWh})$ was obtained at the highest drying air temperature, air velocity and least slice thickness $\left(70^{\circ} \mathrm{C}, 1 \mathrm{~ms}^{-1}\right.$, and $10 \mathrm{~mm}$ ), whereas the maximum energy consumption $(99.78 \mathrm{kWh})$ was obtained at the least air velocity, air temperature and slice thickness $\left(50^{\circ} \mathrm{C}, 1 \mathrm{~ms}^{-1}\right.$, and $\left.10 \mathrm{~mm}\right)$. The maximum and minimum specific energy consumption (150.61 $\mathrm{kWhkg}^{-1}$ and 5.53 $\mathrm{kWhkg}^{-1}$, respectively) were obtained at the first and last drying parameter regimes: $50^{\circ} \mathrm{C}, 20 \mathrm{~mm}, 1.0 \mathrm{~ms}^{-1}$ and $70^{\circ} \mathrm{C}, 10 \mathrm{~mm}, 2$ $\mathrm{ms}^{-1}$, respectively.

Three-dimensional response surface plots of the interaction effects of the process variables on the response variable were developed. The prediction of the desirability function based on $98 \%$ level of confidence in the range of the input variables yielded an optimal process parameters of $1.94 \mathrm{~ms}^{-1}, 10.36 \mathrm{~mm}$ and $68.4^{\circ} \mathrm{C}$ for air velocity, slice thickness and air temperature, respectively. At this optimum input condition, the corresponding energy consumption was obtained as $5.68 \mathrm{kWh}$.

The TUE of the dryer at varying process parameters was in the range of $15-58 \%$. The maximum TUE $(58 \%)$ value was obtained at $70^{\circ} \mathrm{C}$ air temperature, $1.0 \mathrm{~ms}^{-1}$ air velocity and $10 \mathrm{~mm}$ slice thickness treatment combination, whereas the minimum TUE $(15 \%)$ was obtained at $50{ }^{\circ} \mathrm{C}$ air temperature, $2.0 \mathrm{~ms}^{-1}$ air velocity and 20 mm slice thickness.

It is recommended that \pm 0.1 of the optimal drying conditions should be maintained for economy. Further studies on performance analysis and optimisation of energy consumption of solar-electric dryers with heat recovery units for different sliced fruit vegetables are of considerable interest.

\section{References}

Abano E.E., Ma H., Qu W. 2014. Optimisation of drying conditions for quality dried tomato slices using response surface methodology. J. Food Proc. Pres. 38:996-1009.

Afolabi T.J., Akintunde T.Y., Oyelade O.J. 2014. Influence of drying conditions on the effective moisture diffusivity and energy requirements of ginger slices. J. Food Res. 3:103-12.

Arinze E.A., Adefila S.S., Eke B.A. 1990. Experimental evaluation of various designs of free convection solar crop dryer with and without thermal storage. pp 19-23 in Proc. National Conference of the Nigerian Society of Agricultural Engineers, Jun 15-19, University of Makurdi, Nigeria.

Aviara N.A., Onuoha L.N., Falola O.E., Igbeka J.C. 2014. Energy and exergy analysis of native cassava starch drying in a tray dryer. Energy. 73:809-17.

Azadbakht M., Torshizi V.M., Ziaratban A., Aghili H. 2017. Energy and exergy analysis during eggplant drying in a fluidised bed dryer. Agric. Eng. Int. 19:177-82.

Beigi M. 2016. Energy efficiency and moisture diffusivity of apple slices during convective drying. Food Sci. Tech. 36:145-50.

Billiris M.A., Siebenmorgen T.J., Mauromoustakos A. 2011. Estimating the theoretical energy required to dry rice. J. Food Eng.107:253-61.

Darvishi H., Asi R.A., Asghari A., Najafi G., Gazori H.A. 2013. Mathematical modeling, moisture diffusion, energy consumption and efficiency of thin-layer drying of potato slices. J. Food Proc. Tech. 4:215-29.

Eke A.B. 2013. Development of small scale direct mode natural convection solar dryer for tomato, okra and carrot. Int. J. Eng. Tech. 3:199-204.

El-Mesery H.S., Mwithiga G. 2012. Comparison of a gas fired hotair dryer with an electrically heated hot-air dryer in terms of drying process, energy consumption and quality of dried onion slices. Afr. J. Agric. Res. 7:4440-52.

Ferreira A.G., Charbel A.L., Pires R.L., Silva J.G., Maia C.B. 2007. Experimental analysis of a hybrid dryer. J. Therm. Eng. 6:3-7.

Giri S.K., Prasad S. 2007. Optimisation of microwave-vacuum dry- 
ing of button mushrooms using response-surface methodology. Drying Tech. 25:901-11.

Itodo I.N., Obetta S.E., Satimehin A.A. 2002. Evaluation of a solar crop dryer for rural applications in Nigeria. Botswana J. Tech. 11:58-62.

Jindarat W., Rattanadecho V., Pianroj Y. 2011. Analysis of energy consumption in drying process of non-hygroscopic porous pack bed using a combined multi-feed microwave-convective air and continuous belt system. Drying Tech. 29:926-38.

Koyuncu T., Tosun I., Pinar Y. 2007. Drying characteristics and heat energy requirement of cornelian cherry fruits (Cornus mas L.). J Food Eng. 78:735-9.

Kumar D., Prasad S., Murthy G.S. 2011. Optimisation of microwave-assisted hot air drying conditions of okra using response surface methodology. J. Food Sci. Tech. 4:1-13.

Minaei S., Cheuarbon H.A., Motevali A., Arabhosseim A. 2014. Energy consumption, thermal utilisation efficiency and hypericum content in drying leaves of St. John's wort. J. Energ. Southern Afr. 25:27-35.

Motevali A., Minaee S., Babakar A., Ghobadian S., Darvishi H. 2014. Energy analysis and drying kinetics of chamomile leaves in microwave-convective dryer. J. Saudi Soc. Agric. Sci. 3-9. Nwajinka C.O., Onuegbu C.U. 2014. Development of a solar cabinet dryer for root crops chips in Nigeria. J. Agric. Eng. Tech. 22:47-58.

Nwakuba N.R., Asoegwu S.N., Nwaigwe K.N. 2016. Energy requirements for drying of sliced agricultural products: a review. Agric. Eng. Int. CIGR. 18:144-55.

Nwakuba N.R., Asoegwu S.N., Nwaigwe K.N., Chukwuezie C.O. 2017. Design and development of a hybrid solar-electric dryer for sliced vegetable crops. J. Agric. Eng. Tech. 2:48-64.

Sarsavadia P.N. 2007. Development of a solar-assisted dryer and evaluation of energy requirement for the drying of onion. Ren. Energ. 32:2529-47.

Sepehrimehr B., Kohan A. 2015. Evaluating a hybrid passive solarelectrical dryer for drying grapes. Adv. Env. Biol. 9:353-5.

Sharma G.P., Prasad K.S. 2006. Optimisation of process parameters for microwave drying of garlic cloves. J. Food Eng. 75:441-6.

Tripathy P.P., Kumar S. 2009. Modeling of heat transfer and energy analysis of potato slices and cylinders during solar drying. J. App. Therm. Eng. 29:884-91. 